Research Paper

\title{
A primary assessment of the endophytic bacterial community in a xerophilous moss (Grimmia montana) using molecular method and cultivated isolates
}

\author{
Xiao Lei Liu, Su Lin Liu, Min Liu, Bi He Kong, Lei Liu, Yan Hong Li \\ College of Life Science, Capital Normal University, Haidian District, Beijing, China.
}

Submitted: December 27, 2012; Approved: April 1, 2013.

\begin{abstract}
Investigating the endophytic bacterial community in special moss species is fundamental to understanding the microbial-plant interactions and discovering the bacteria with stresses tolerance. Thus, the community structure of endophytic bacteria in the xerophilous moss Grimmia montana were estimated using a 16S rDNA library and traditional cultivation methods. In total, 212 sequences derived from the 16S rDNA library were used to assess the bacterial diversity. Sequence alignment showed that the endophytes were assigned to 54 genera in 4 phyla (Proteobacteria, Firmicutes, Actinobacteria and Cytophaga/Flexibacter/Bacteroids). Of them, the dominant phyla were Proteobacteria (45.9\%) and Firmicutes (27.6\%), the most abundant genera included Acinetobacter, Aeromonas, Enterobacter, Leclercia, Microvirga, Pseudomonas, Rhizobium, Planococcus, Paenisporosarcina and Planomicrobium. In addition, a total of 14 species belonging to 8 genera in 3 phyla (Proteobacteria, Firmicutes, Actinobacteria) were isolated, Curtobacterium, Massilia, Pseudomonas and Sphingomonas were the dominant genera. Although some of the genera isolated were inconsistent with those detected by molecular method, both of two methods proved that many different endophytic bacteria coexist in G. montana. According to the potential functional analyses of these bacteria, some species are known to have possible beneficial effects on hosts, but whether this is the case in G. montana needs to be confirmed.
\end{abstract}

Key words: bacterial diversity, endophytes, moss, molecular method, cultivated isolates.

\section{Introduction}

In plant-endophyte interactions, plants provide nutrients and residency for the bacteria, while the bacteria in exchange directly or indirectly improve plant growth and health (Mastretta et al., 2006). Once inside the plant, endophytes either reside in specific plant tissues such as the root cortex or the xylem, or colonize the plant systematically by transport through the vascular system or the apoplast (Quadt-Hallmann et al., 1997). Of the nearly 300000 plant species on earth, each species is host to one or more species of endophytes (Strobel et al., 2004). The complete description of endophytic species has only been enumerated and characterized for a handful of plant species, and the majority of these are common higher plants. Few studies have examined the endophytes of bryophytes, which represent the simplest extant land plants and have been classified by prominent bryologists as "living fossils" (Hornschuh et al., 2002). Consequently, the opportunity to find new and beneficial endophytic microorganisms among the diversity of plants in different ecosystems is considerable.

The mosses, one kind of bryophytes, are a diverse group of land plants that usually colonize habitats with either moist or extremely variable conditions. One of their most important features is their life cycle, which involves alteration between a diploid sporophyte and a dominant free-living haploid gametophyte generation (Opelt and Berg, 2004). Mosses are unique host plants for microorganisms in numerous ways. For example, the small size of mosses results in limited availability of the substratum. In addition, most mosses display an extraordinarily high tolerance to extreme desiccation and can resume normal metabolism very rapidly after rehydration. Hence, successful microbial colonization requires adaptation to these special 
conditions (DoĖbbeler, 1997). Analysis of the epiphytes on the gametophyte of Funaria hygrometrica detected numerous bacterial species on the surface of the phylloid. Among these species, two Methylobacterium strains were found to be able to simulate the well-known effect of cytokinin application on bud formation in Funaria protonema and they also promoted the growth of protonemal filaments (Hornschuh et al., 2002). Endophytic methanotrophic bacteria were also found in the hyaline cells and on the stem leaves of Sphagnum mosses; here, they provided carbon for photosynthesis via in situ oxidation of methane to carbon dioxide (Raghoebarsing et al., 2005).

Opelt and Berg (2004) isolated and identified many antagonistic bacteria associated with three moss species (Tortula ruralis, Aulacomnium palustre and Sphagnum rubellum) in the nutrient-poor habitats of the Baltic Sea Coast in Germany. These species belong to nine different genera, among which Burkholderia, Pseudomonas and Serratia were dominant, but the richness and diversity of antagonistic species were moss species-dependent, and the highest number of species with antagonistic activity was isolated from S. rubellum. Another study examined the function and diversity of bacterial species associated with two Sphagnum species (S. fallax and S. magellanicum) that grow in a temperate mire ecosystem. Species belonging to the genus Burkholderia were predominant in Sphagnum species and this genus was possibly involved in antagonism/pathogen defense and nitrogen-fixation. The authors concluded that Sphagnum is a reservoir for powerful and extraordinary antagonists and potentially facultative human pathogens (Opelt et al., 2007). Thus, thorough research on the bacteria associated with other mosses in different niches would be also useful in discovering bacterial resources and helpful in understanding the interactions between mosses and their associated microbes.

Grimmia montana is a xerophilous moss, and has a high tolerance to drought, cold and UV radiation (Yi and Liu, 2007), and can often be found growing in extreme environments. It always lives under extreme desiccation conditions and can resume normal metabolism very rapidly after rehydration. In this paper, our aim is to study the diversity and community structure of its endophytes using 16S rDNA library and culture-dependent approaches, and hope to make a well known on the interactions between endophytes and G. montana and try to find some bacterial resources with the strong tolerance to the stresses.

\section{Material and Methods}

\section{Sampling and surface disinfection}

Grimmia montana were sampled from the surface of one large stone in Beijing Songshan National Nature Reserve located at an altitude of $890 \mathrm{~m}$, at N: $40^{\circ} 31^{\prime} 00.45^{\prime \prime}$ by E: $115^{\circ} 49^{\prime} 33.20^{\prime \prime}$ on the $19^{\text {th }}$ of April, 2011. About $3 \mathrm{~g}$ of plant material, approximately more than one thousand of entire plants was collected after absorbing enough water, and then mixed together and immediately transported to the laboratory for surface disinfection as described previously (Li et al., 2010). The plants were first washed many times with tap water to remove attached substratum. Subsequently, they were immersed in $70 \%$ ethanol for $3 \mathrm{~min}$, washed with $15 \%$ sodium hypochlorite solution for $10 \mathrm{~min}$, rinsed three times with $70 \%$ ethanol for $30 \mathrm{~s}$, and finally washed five times with sterile distilled water. To confirm that the disinfection process was successful, aliquots of the sterile distilled water in the final rinse were used to determine the results of surface disinfection. Bacteria were cultivated by setting $100 \mu \mathrm{L}$ of the final rinse on R2A and TSA medium plates, and then examining the plates for bacterial growth after incubation at $28^{\circ} \mathrm{C}$ for 3 days. Molecular detection of bacterial species was accomplished by $16 \mathrm{~S}$ rRNA gene PCR detection based on the primers $799 \mathrm{f}$ (5'-AACAGGATTAGATACCCTG-3') and 1492r (5'-GGTTACCTTGTTACGACTT-3') (Chelius and Triplett, 2001) using the final rinse as template. The $50 \mu \mathrm{L}$ PCR reaction mixture contained $5 \mu \mathrm{L}$ of the final rinse, $5 \mu \mathrm{L} \mathrm{10x}$ Taq reaction buffer (including $1.5 \mathrm{mM} \mathrm{MgCl}_{2}$ ), 10 pmol of each primer, $200 \mu \mathrm{M}$ each dNTP, and $1.5 \mathrm{U}$ of Taq DNA polymerase (Takara Co.). After initial denaturation at $94{ }^{\circ} \mathrm{C}$ for five minutes, each thermal cycling was as follows: denaturation at $94{ }^{\circ} \mathrm{C}$ for one minute, annealing at $53{ }^{\circ} \mathrm{C}$ for one minute, and elongation at $72{ }^{\circ} \mathrm{C}$ for one minute. At the end of 30 cycles, the final extension step was at $72{ }^{\circ} \mathrm{C}$ for $15 \mathrm{~min}$. Products of four parallel PCRs were combined and electrophoretically separated by $1 \%$ agarose. Finally, plant samples were determined to be successfully surface disinfected if no bacterium was identified via cultivation and PCR. These plants were used for the subsequent analyses.

\section{DNA extraction and amplification of the bacterial 16S rRNA genes}

About $2 \mathrm{~g}$ of surface-disinfected G. montana was frozen with liquid nitrogen and ground to a fine powder in a sterilized and precooled mortar. Next, the cetyltrimethylammonium bromide (CTAB) procedure was used to extract total DNA as previously described (Xie et al., 1999). The DNA was resuspended in $150 \mu \mathrm{L}$ sterile Milli-Q water. The primer pair $799 \mathrm{f}$ and $1492 \mathrm{r}$ was selected to amplify the $16 \mathrm{~S}$ rDNA of the endophytic bacteria. The PCR reaction mixture and programs are the same as described above in the section of surface disinfection. We excised the approximately 730 bp band from a $1 \%$ agarose gel, following electrophoresis of the DNA, and purified the DNA using the Gel Extraction Kit (Omega Co.), as described by the manufacturer.

\section{Construction of the 16S rDNA clone library}


The purified $730 \mathrm{bp}$ PCR products were ligated into the pMD18-T vector (Takara Co.). Escherichia coli Top10 competent cells (Tiangen Co.) were transformed with the ligation products and spread onto Luria-Bertani agar plates with ampicillin (100 $\left.\mathrm{mg} \mathrm{L}^{-1}\right)$ for standard blue and white screening (Sambrook et al., 1989). Randomly selected colonies were screened directly for inserts by performing colony PCR with primers RV-M (5'-GAGCGGATAACAATTTCACACAGG-3') and M13-47 (5'-CGCCAGGGTTTTCCCAGTCACGAC-3') for the vector (Takara Co.). Two hundred fifty clones containing inserts of the correct size were sequenced using an ABI PRISM 3730 automatic sequencer (Shanghai Sangon Co., Ltd).

\section{Phylogenetic analysis}

After being trimmed by cutting the vector sequences using the Editseq program in the DNAStar package (Burland, 2000) and removing all the bad sequences as determined by the chimera sequence detection software Mallard 1.02 (www.cardiff.ac.uk/biosi/research/biosoft), all other manually verified nucleotide sequences were submitted to the NCBI GenBank database. Clones of 16S rRNA gene sequences showing $97 \%$ similarity or higher were considered to belong to the same phylotype by sequencher 4.8 (Gene Codes, Ann Arbor, MI) and assigned to an Operational Taxonomic Unit (OTU). Sequences of all phylotypes were compared to the NCBI database using BlastN or aligned by the identify analysis of EzTaxon-e (Kim et al., 2012). Clones with a $16 \mathrm{~S}$ rDNA sequence similarity larger than $97 \%$ were assigned to the same species; those with $>95 \%$ identity were assigned to the same genus; those with $<95 \%$ were determined to be uncultured bacterial species. Next, those sequences assigned to uncultured bacteria were aligned using Clustal W (Thompson et al., 1994), and tree constructions were done with the MEGA 5 program package (Tamura et al., 2011) using the neighbor-joining method (Saitou and Nei, 1987) to infer their classification. Bootstrap analysis was performed with 1,000 replicates.

\section{Estimation of the size of the clone library}

To estimate the representation of the library, the clone coverage was calculated with the following equation based on the sequencing results: $C=(1-n 1 / N) \times 100 \%$, where $n 1$ represents the number of phylotypes occurring only once and $N$ is the number of clones being examined. Diversity of the clone library was investigated using rarefaction analysis. Rarefaction curve was calculated using the Ecosim 7.0 software (Gotelli and Entsminger, 2004).

Isolation of culturable endophytes and determination of CFU

To isolate the endophytes from the plants, $1 \mathrm{~mL}$ of sterile $0.85 \% \mathrm{NaCl}$ was added to $0.5 \mathrm{~g}$ (fresh weight) of surface disinfected G. montana and samples were homoge- nized in a small sterile mortar. The resultant mixture was serially diluted with sterile $0.85 \% \mathrm{NaCl}$ and plated onto R2A and TSA media (Difco, Detroit, MI). Plates were incubated for 3 days at $28{ }^{\circ} \mathrm{C}$, after which Colony-Forming Units (CFU) were counted to calculate the average number of colonies per gram of moss. Isolates obtained by plating were purified and stored at $-70{ }^{\circ} \mathrm{C}$ in sterile broth containing $40 \%$ glycerol.

\section{ARDRA analysis and identification of the isolates by sequencing}

$1 \mathrm{uL}$ of the bacterial suspension derived from each isolate was used to amplify the 16S rDNA fragments using the primers $27 \mathrm{f}$ and $1492 \mathrm{r}$. The PCR reaction mixture and programs are the same as described above in the section on surface disinfection. The approximately $1490 \mathrm{bp}$ band was excised from a $0.8 \%$ agarose gel, and purified using the Gel Extraction Kit (Omega Co.) as described by the manufacturer. Next, the purified products were enzymatically digested with Hae III and $H$ ha I at $37^{\circ} \mathrm{C}$ for $4 \mathrm{~h}$, respectively. According to their electrophoresis pattern on a $1.0 \%$ agarose gel, these isolates were classified into different OTUs. Finally, the PCR products of isolates with different OTUs were sequenced using an ABI PRISM 3730 automatic sequencer (Shanghai Sangon Co., Ltd). After trimming the low quality nucleotides, the sequence similarities were calculated using the EzTaxon-e (Kim et al., 2012).

\section{Results}

\section{S rDNA library analysis of endophytic bacterial community}

Bacterial 16S rDNA fragments were amplified from total DNA that was extracted from surface disinfected $G$. montana, using the primers $799 \mathrm{f}$ and $1492 \mathrm{r}$. The amplified DNA displayed only one distinct and one weak band, of approximately $730 \mathrm{bp}$ and $1000 \mathrm{bp}$, respectively. The sequencing result showed that the $730 \mathrm{bp}$ band represented the bacterial 16S rRNA fragment, while the $1000 \mathrm{bp}$ fragment was mainly derived from the mitochondria of the mosses. Thus, the purified $730 \mathrm{bp}$ PCR products were used to construct a $16 \mathrm{~S}$ rDNA clone library for the endophytic bacteria.

Of 250 clones, two-hundred and twelve individual sequences were verified. They were determined as 90 phylotypes by sequencher 4.8 and the sequences were deposited in GenBank (Accession No.: JX042330-JX042419). Of them, 48 phylotypes occurring only once, and the calculated coverage of the clone library was $77.4 \%$. The rarefaction curve also showed that the clones detected could reflect the main information of endophytes (Figure 1).

Sequence alignment revealed that 196 individual sequences exhibited $>95 \%$ similarity with those of cultivable bacteria. Of these, 90 clones (45.9\%) were affiliated with Proteobacteria, 54 clones (27.6\%) with Firmicutes, 29 
$(14.8 \%)$ with Actinobacteria, and 23 (11.7\%) with Cytophaga/Flavobacterium/Bacteroides (CFB) group. Details of all alignments in the clone library are listed in Table 1.

The sequences attributed to Proteobacteria, which includes alpha, beta and gamma classes, made up the largest fraction of the clone library. Of the 90 clones affiliated with Proteobacteria, 67 clones (or $74.4 \%$ ) exhibited high similarity to Gammaproteobacteria. The proportion of clones that grouped with the alpha and beta classes was $20 \%$ and $5.6 \%$, respectively. However, there were no sequences with $>95 \%$ similarity to genera in the delta or epsilon class. The 67 clones of Gammaproteobacteria were related to four orders of bacteria, including Pseudomonadales (34 clones), Enterobacteriales (22 clones), Aeromonadales (10 clones) and Xanthomonadales (1 clone). Of these, the dominant genera include: Acinetobacter, Aeromonas, Citrobacter, Enterobacter, Leclercia, Pseudomonas and Psychrobacter; the dominant species were Acinetobacter johnsonii, Acinetobacter junii, Leclercia adecarboxylata, Aeromonas punctata and Enterobacter cancerogenus (Table 1). Alphaproteobacteria was the second-most abundant subgroup of Proteobacteria in our survey. The 18 clones in this subgroup represented bacteria in four orders (Rhizobiales, Sphingomonadales, Rhodobacterales and Caulobacterales) (Table 1). The dominant genera were Brevundimonas, Microvirga, Rhizobium and Sphingomonas. Of the 5 clones affiliated with Betaproteobacteria, four belonged to bacterial species in Burkholderiales and only one was grouped into Methylophilales. All of them were assigned to different genera, including Bordetella, Comamonas, Methylophilus, Ramlibacter and Variovorax (Table 1).

Among the non-Proteobacteria, 54, 29 and 23 clones exhibited high similarity to bacterial species in the phyla Firmicutes, Actinobacteria and CFB respectively (Table 1). In Firmicutes, 43 clones were closely related to bacteria in Bacillales, 9 clones to Clostridiales and only 2 to Lactobacillales. The dominant genera included Paenisporosarcina, Planococcus, Planomicrobium, and the most abundant species were Paenisporosarcina macmurdoensis and Planococcus rifietoensis. Of the 29 clones grouped into Actinomycetales of phylum Actinobacteria, twelve clones were grouped with the Arthrobacter genus, while the others grouped with many other genera including Aeromicrobium and Ornithinicoccus (Table 1). Arthrobacter sulfonivorans was the most common species. In the 23 clones belonging to the CFB phylum, bacteria occurred in four orders, the Sphingobacteriales, Cytophagales, Bacteroidales and Flavobacteriales. The dominant genera were Adhaeribacter and Segetibacter, and Segetibacter koreensis was the most common species.

Finally, the 16S rDNA sequence of 16 clones, showed $<95 \%$ similarity to the previously cultivated bacteria. The phylogenetic analysis showed that these clones exhibited a close relationship with Actinobacteria (4 clones),
Alphaproteobacteria (3 clones), Acidobacteria (3 clones), Bacteroidetes ( 2 clones), Betaproteobacteria (1 clone) and Firmicutes (3 clones) (Figure 2).

\section{Endophytic bacteria communities detected by cultivation method}

The isolation result showed that the number of colony-forming units (CFU) as determined for samples grown on R2A medium was higher than the number of CFUs grown on TSA medium. The counts (expressed as $\mathrm{g}^{-1}$ fresh weight) were $2.0^{*} 10^{5}$ and $3.3 * 10^{4}$ on R2A and TSA medium, respectively. Totally 49 isolates were sequenced on the basis of 16S rDNA fragments, the ARDRA analysis resulted in the delimitation of 14 OTUs. Based on their $16 \mathrm{~S}$ rDNA sequences (Genbank no. JX042420 - JX042433), they were assigned to 8 genera in three phyla (Proteobacteria, Actinobacteria and Firmicutes). The strains that were successfully cultivated included some genera in the Proteobacteria (Burkholderia, Massilia, Pseudomonas, Spingomonas, Yersinia), and some genera in Firmicutes and Actinobacteria such as Curtobacterium, Brevibacterium and Streptomyces. The most abundant species were Curtobacterium flaccumfaciens, Massilia brevitalea, Pseudomonas azotoformans and Pseudomonas libanensis (Table 2).

Compared the above bacterial communities with those discovered by $16 \mathrm{~S}$ rDNA library technique, the cultivated species only involved in three phyla (Firmicutes, Proteobacteria and Actinobacteria) and no bacteria in group $\mathrm{CFB}$ was cultivated. The species and genera discovered by cultivation were much less than those detected by molecular method. In addition, some of genera cultivated also could not be found by molecular method, like Curtobacterium, Massilia, Burkholderia and Yersinia.

\section{Discussion}

In this study, we provide a thorough description of the endophytic bacterial community of G. montana, using a combined approach of molecular methods and cultivationdependent techniques. G. montana individuals were sampled from stone surfaces poor in nutrient availability and subject to strong stresses, such as a wide range of temperatures and extreme drought conditions. As far as we know, ours is the first description to date of the endophytic community of a xerophilous moss species in the Grimmiaceae.

Bacterial species detected by $16 \mathrm{~S}$ rDNA library technique belong to 4 phyla and 54 genera, with a high proportion of Gammaproteobacteia, Firmicutes and Actinobacteria. Isolates from $\mathrm{R} 2 \mathrm{~A}$ and TSA media also discovered species in these groups, no bacteria in phylum CFB was cultivated. Although some of the genera discovered by these two methods were inconsistant, it reflected that using the combination of $16 \mathrm{~S}$ rDNA library and cultivated method would be helpful to discover the bacterial in- 
formation completely. Both of them proved that many different species coexisted in this small host (G. montana).

Compared to published accounts of bacterial communities associated with other moss species growing in peat bog, such as Sphagnum, our study revealed the different endophytes inhabiting the tissue of G. montana. In previous studies, Serratia and Pseudomonas of the Gammaproteobacteria, Burkholderia of the beta subgroup, Methylocella and Methylocapsa of the alpha subgroup (Raghoebarsing et al., 2005) and Staphylococcus of the Firmicutes (Opelt et al., 2007) were reported to be associated with Sphagnum species. In this survey, of the Gammaproteobacteria subgroup, Acinetobacter, Leclercia and Aeromonas were the dominant genera. Rhizobium of the Alphaproteobacteria, Massilia, Burkholderia and five of other genera of betaproteobacteria were also detected. In addition, there were also a high proportion of Gram positive bacteria detected in our library. Of them, clones assigned to Firmicutes comprised $25.5 \%$ of the total. Planococcus, Paenisporosarcina, Planomicrobium and Bacillus were the dominant genera; while Arthrobacter and Curtobacterium of Actinobacteria were also abundant. The inconsistent endophytic bacterial community in G. montana and Sphagnum species proved that plant species and niches could cooperatively shape the structure of endophytic bacterial communities (Berg and Smalla, 2009).

Analyzing the function of those bacteria dominanted in G. montana would be helpful to understand the interactions between endophytes and hosts. Of gammaproteobacteria class, the dominant species Acinetobacter johnsonii has been reported to produce alkaline and lowtemperature lipase (Wang et al., 2011a); Acinetobacter junii was considered to be a kind of cellulolytic bacterium that can produce xylanase, cellulose and pectinase (Lo et al., 2010; Zhai et al., 2010) and also could remove (via accumulation) phosphate from synthetic wastewater (Hrenovic et al., 2010); Leclercia adecarboxylata could degrade two and three benzene-ring polycyclic aromatic hydrocarbon compounds (Sarma et al., 2004; Sarma et al., 2010); Aeromonas veronii and Aeromonas punctata subsp. caviae, could produce enzymes such as the amino acid racemase, and xylanase (Cao et al., 2007; Cruz et al., 2008; Silver et al., 2011). As with the Sphagnum bacterial communities, Pseudomonas was also the dominant genus in our study. The isolated species Pseudomonas azotoformans (Komeda et al., 2004; Nie et al., 2011) could degrade Cyhalofop-butyl, while Pseudomonas libanensis could produce the biosurfactant viscosin (Dabboussi et al., 1999; Saini et al., 2008). Rhizobium pusense of the Alphaproteobacteria was first isolated from the rhizosphere of chickpea plants and considered to be a non-symbiotic rhizobium. In our survey utilizing a $16 \mathrm{~S}$ rDNA library, five clones of Rhizobium pusense were detected, indicating that this species could be in symbiosis with $G$. montana.

Of bacteria assigned to Firmicutes, Planococcus rifietensis and Paenisporosarcina macmurdoensis were the dominant species, which have ever been previously isolated from algal or cyanobacterial mats in sulfurous springs (Reddy et al., 2003; Romano et al., 2003). Four Planomicrobium species were also found, which have been previously isolated from coastal sediments (Dai et al., 2005), seafood jeotgal (Yoon et al., 2001) and glaciers (Zhang et al., 2009a); they were considered as the cold tolerant bacteria (Yang et al., 2011; Zhang et al., 2009a). In addition, Bacillus simplex was isolated by cultivation, which was ever provided to have strong antioxidant activity (Wang et al., 2011b). Among the Actinobacteria, Arthrobacter sulfonivorans could produce membrane-associated dimethylsulfone- and dimethylsulfoxide-reductases (Borodina et al., 2002); Arthrobacter agilis could release N,N-dimethyl-hexadecanamine (dimethylhexadecylamine) to directly affect plant morphogenesis (Fong et al., 2001; Velazquez-Becerra et al., 2011) and could contribute to membrane stabilization in response to thermal and salt stress by increasing carotenoid accumulation (Fong et al., 2001); Curtobacterium was a dominant genus discovered in the cultures, and Curtobacterium flaccumfaciens, as the most dominant species in this group, also was known to reduce symptoms caused by Xylella fastidiosa in Catharanthus roseus (Lacava et al., 2007); the

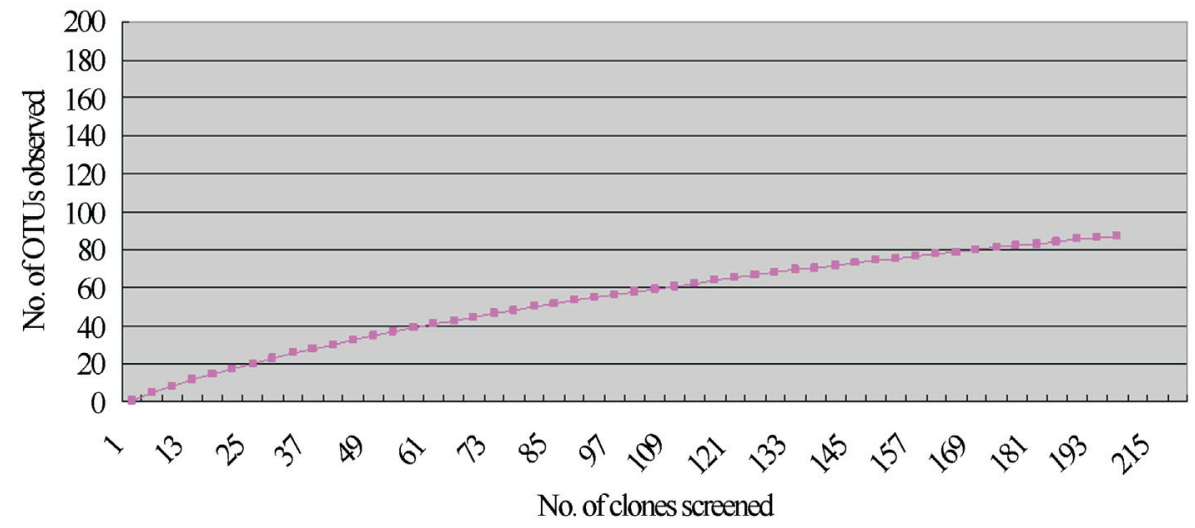

Figure 1 - Rarefaction curve for the endophytic bacterial 16S rDNA clone library of Grimmia montana. 
cultivable Streptomyces griseoplanus could produce anticapsin and Erythromycin-a, and might probably help to resist pathogens in the host (Boeck et al., 1971; Thompson et al., 1971).

The dominant species Segetibacter koreensis from CFB phylum was first isolated from ginseng fields in South Korea (An et al., 2007), while Adhaeribacter tereus and Adhaeribacter aquaticus were ever isolated from soil (Zhang et al., 2009b) and water biofilms (Rickard et al., 2005), respectively. This is the first time that these species have been found as endophytes, and their possible functions remain unclear.

In conclusion, the most important findings of this study were: (1) a high endophytic bacterial diversity and complex community structure were found associated with G. montana, using a combination of molecular and cultivation techniques; (2) community structure differed from that of endophytic communities of Sphagnum mosses, especially in the abundance of Actinobacteria and Firmicutes (higher in G. Montana); and (3) Some bacterial species found endophytically in G. montana are known to have possible beneficial effects on plants, but whether this is the case in G. Montana is not proven. Thus, in order to improve our understanding of the concrete mechanisms through which endophytic bacteria (such as those of G. montana) adapt to extreme environments and discover new bacterial resources, further work needs to be done in the future.

\section{Acknowledgments}

We would like to thank E.B.M. Drummond at the University of British Columbia for her assistance with English language and grammatical editing of the manuscript. We also thank professor Guisen Du at Capital Normal University for the species identification of moss. This work was funded by the Scientific Research Program of National Natural Science Foundation of China (No. 31100004).

\section{References}

An DS, Lee HG, Im WT, Liu OM, Lee ST (2007) Segetibacter koreensis gen. nov., sp nov., a novel member of the phylum Bacteroidetes, isolated from the soil of a ginseng field in South Korea. Int J Syst Evol Microbiol 57:1828-1833.

Berg G, Smalla K (2009) Plant species and soil type cooperatively shape the structure and function of microbial communities in the rhizosphere. FEMS Microbiol Ecol 68:1-13.

Boeck LD, Christy KL, Shah R (1971) Production of Anticapsin by Streptomyces griseoplanus. Appl Microbiol 21:10751079.

Borodina E, Kelly DP, Schumann P, Rainey FA, Ward-Rainey NL, Wood AP (2002) Enzymes of dimethylsulfone metabolism and the phylogenetic characterization of the facultative methylotrophs Arthrobacter sulfonivorans sp. nov., Arthrobacter methylotrophus sp. nov., and Hyphomicrobium sulfonivorans sp. nov. Arch Microbiol 177:173-183.
Burland TG (2000) DNASTAR's Lasergene sequence analysis software. Methods Mol Biol 132:71-91.

Cao HP, Yang XL, Wang YH, Li YY (2007) Isolation and growth characteristics of pathogenic Aeromonas punctata caviae from Sturgeons. Chinese J Zool 42:1-6.

Chelius M, Triplett E (2001) The diversity of archaea and bacteria in association with the roots of Zea mays L. Microbial Ecol 41:252-263.

Cruz A, Caetano T, Suzuki S, Mendo S (2008) Aeromonas veronii, a tributyltin (TBT)-degrading bacterium isolated from an estuarine environment, Ria de Aveiro in Portugal (vol 64, pg 639, 2007). Mar Environ Res 66:309-309.

Dabboussi F, Hamze M, Elomari M, Verhille S, Baida N, Izard D, Leclerc H (1999) Pseudomonas libanensis sp. nov., a new species isolated from Lebanese spring waters. Int. J Syst Bacteriol 49:1091-1101.

Dai X, Wang YN, Wang BJ, Liu SJ, Zhou YG (2005) Planomicrobium chinense sp. nov., isolated from coastal sediment, and transfer of Planococcus psychrophilus and Planococcus alkanoclasticus to Planomicrobium as Planomicrobium psychrophilum comb. nov. and Planomoicrobium alkanoclasticum comb. nov. Int J Syst Evol Microbiol 55:699-702.

DoÈbbeler P (1997) Biodiversity of bryophilous ascomycetes. Biodivers Conserv 6:721-738.

Fong NJC, Burgess ML, Barrow KD, Glenn DR (2001) Carotenoid accumulation in the psychrotrophic bacterium Arthrobacter agilis in response to thermal and salt stress. Appl Microbiol Biot 56:750-756.

Gotelli NJ and Entsminger GL (2004) EcoSim: Null models software for ecology. Version 7. Acquired Intelligence Inc. \& Kesey-Bear. Jericho, VT 05465. Available at: http://garyentsminger.com/ecosim/index.htm.

Hornschuh M, Grotha R, Kutschera U (2002) Epiphytic bacteria associated with the bryophyte Funaria hygrometrica: Effects of methylobacterium strains on protonema development. Plant Biology 4:682-687.

Hrenovic J, Tibljas D, Ivankovic T, Kovacevic D, Sekovanic L (2010) Sepiolite as carrier of the phosphate-accumulating bacteria Acinetobacter junii. Appl Clay Sci 50:582-587.

Kim OS, Cho YJ, Lee K, Yoon SH, Kim M, Na H, Park SC, Jeon YS, Lee JH, Yi H et al. (2012) Introducing EzTaxon-e: a prokaryotic $16 \mathrm{~S}$ rRNA gene sequence database with phylotypes that represent uncultured species. Int J Syst Evol Microbiol 62:716-721.

Komeda H, Harada H, Washika S, Sakamoto T, Ueda M, Asano Y (2004) S-Stereoselective piperazine-2-tert-butylcarboxamide hydrolase from Pseudomonas azotoformans IAM 1603 is a novel L-amino acid amidase. Eur J Biochem 271:1465-1475.

Lacava PT, Li W, Araujo WL, Azevedo JL, Hartung JS (2007) The endophyte Curtobacterium flaccumfaciens reduces symptoms caused by Xylella fastidiosa in Catharanthus roseus. J Microbiol 45:388-393.

Li YH, Zhu JN, Zhai ZH, Zhang QA (2010) Endophytic bacterial diversity in roots of Phragmites australis in constructed Beijing Cuihu Wetland (China). FEMS Microbiol Lett 309:84-93.

Lo YC, Lu WC, Chen CY, Chen WM, Chang JS (2010) Characterization and high-level production of xylanase from an in- 


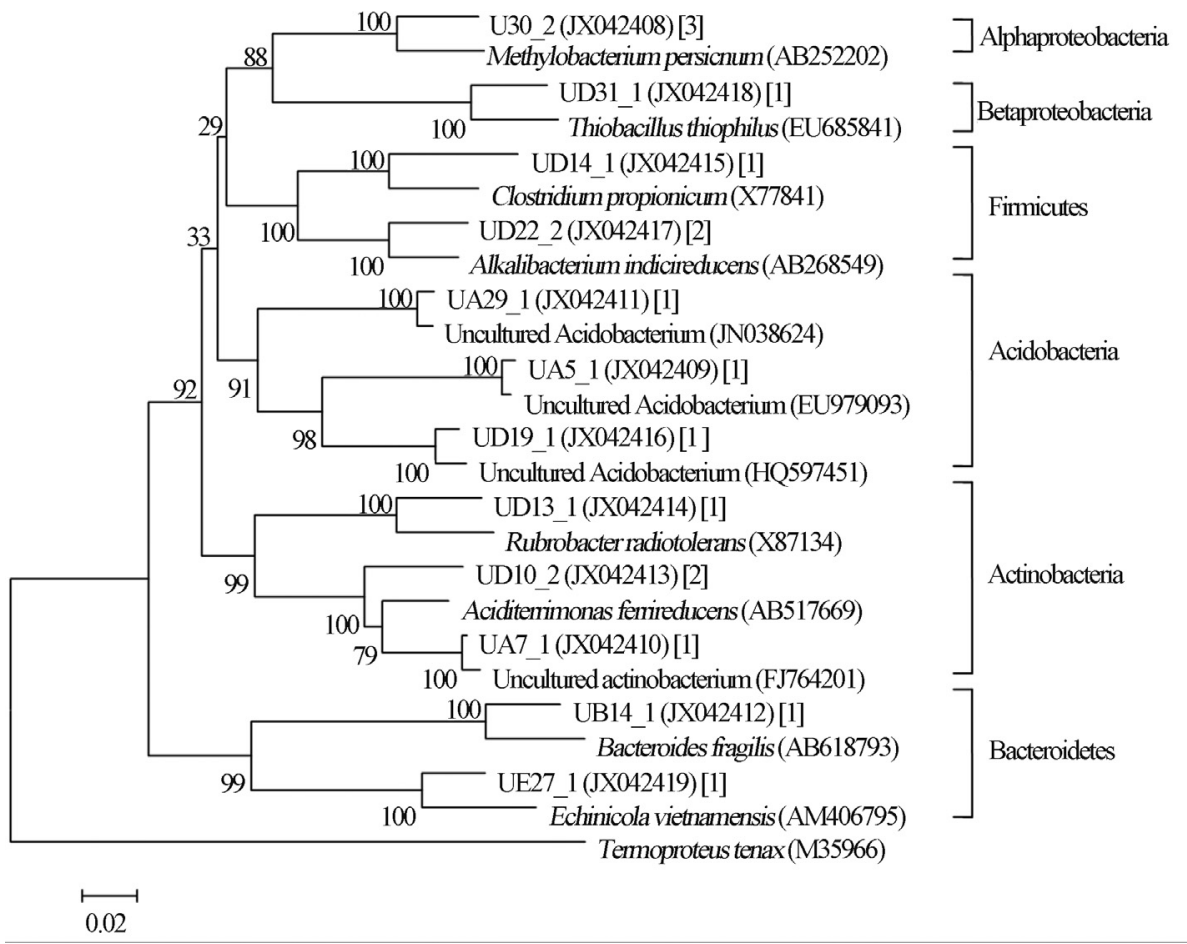

Figure 2 - 16S rDNA-based dendrogram showing the phylogenetic relationships of uncultured endophytic bacterial clones from Grimmia montana. Phylogeny was inferred using a neighbor-joining analysis and trees were generated using MEGA5 software. Numbers in parentheses represent the sequence accession numbers in GenBank. Numbers in square brackets indicate the number of clones out of the total clones. Numbers at branch points indicate bootstrap values. The scale bar represents a $2 \%$ estimated difference in nucleotide sequence.

digenous cellulolytic bacterium Acinetobacter junii F6-02 from southern Taiwan soil. Biochem Eng J 53:77-84.

Mastretta C, Barac T, Vangronsveld J, Newman L, Taghavi S, Van der Lelie D (2006) Endophytic bacteria and their potential application to improve the phytoremediation of contaminated environments. Biotechnol Genet Eng 23:175-207.

Nie ZJ, Hang BJ, Cai S, Xie XT, He J, Li SP (2011) Degradation of cyhalofop-butyl (CyB) by Pseudomonas azotoformans strain QDZ-1 and cloning of a novel gene encoding CyBhydrolyzing esterase. J Agr Food Chem 59:6040-6046.

Opelt K, Berg C, Berg G (2007) The bryophyte genus Sphagnum is a reservoir for powerful and extraordinary antagonists and potentially facultative human pathogens. FEMS Microbiol Ecol 61:38-53.

Opelt K, Berg G (2004) Diversity and antagonistic potential of bacteria associated with bryophytes from nutrient-poor habitats of the Baltic Sea coast. Appl Environ Microb 70:65696579.

Zhai QM, Xue WW, Xue YC, Zheng LJ (2010) Optimizations of fermentation for pectinase production with Acinetobacter junii FM208850. Biotechnology 20:65-69. (in Chinese)

Quadt-Hallmann A, Benhamou N, Kloepper JW (1997) Bacterial endophytes in cotton: Mechanisms of entering the plant. Can J Microbiol 43:577-582.

Raghoebarsing AA, Smolders AJP, Schmid MC, Rijpstra WIC, Wolters-Arts M, Derksen J, Jetten MSM, Schouten S, Damste JSS, Lamers LPM et al. (2005) Methanotrophic symbionts provide carbon for photosynthesis in peat bogs. Nature 436:1153-1156.

Reddy GSN, Matsumoto GI, Shivaji S (2003) Sporosarcina macmurdoensis sp. nov., from a cyanobacterial mat sample from a pond in the McMurdo Dry Valleys, Antarctica. Int J Syst Evol Microbiol 53:1363-1367.

Rickard AH, Stead AT, O'May GA, Lindsay S, Banner M, Handley PS, Gilbert P (2005) Adhaeribacter aquaticus gen. nov., sp. nov., a Gram-negative isolate from a potable water biofilm. Int J Syst Evol Microbiol 55:821-829.

Romano I, Giordano A, Lama L, Nicolaus B, Gambacorta A (2003) Planococcus rifietensis sp. nov, isolated from algal mat collected from a sulfurous spring in Campania (Italy). Syst Appl Microbiol 26:357-366.

Saini HS, Barragan-Huerta BE, Lebron-Paler A, Pemberton JE, Vazquez RR, Burns AM, Marron MT, Seliga CJ, Gunatilaka AAL, Maier RM (2008) Efficient purification of the biosurfactant viscosin from Pseudomonas libanensis strain M9-3 and its physicochemical and biological properties. J Nat Prod 71:1011-1015.

Saitou N, Nei M (1987) The neighbor-joining method - a new method for reconstructing phylogenetic trees. Mol Biol Evol 4:406-425.

Sambrook J, Fritsch EF, Maniatis T (1989) Molecular cloning: A laboratory manual. 2nd edtion edn: Cold Spring Harbor Laboratory Press.

Sarma PM, Bhattacharya D, Krishnan S, Lal BW (2004) Degradation of polycyclic aromatic hydrocarbons by a newly discovered enteric bacterium, Leclercia adecarboxylata. Appl Environ Microb 70:3163-3166.

Sarma PM, Duraja P, Deshpande S, Lal B (2010) Degradation of pyrene by an enteric bacterium, Leclercia adecarboxylata PS4040. Biodegradation 21:59-69.

Silver AC, Williams D, Faucher J, Horneman AJ, Gogarten JP, Graf J (2011) Complex evolutionary history of the 
Table 1 - Identity of the clones based on 16S rDNA sequence similarity.

\begin{tabular}{|c|c|c|c|c|}
\hline Group & Number of clones & The closest match & Accession No. & Sequence similarity $\%$ \\
\hline \multirow[t]{15}{*}{ Gammaproteobacteria } & 67 & & & \\
\hline & 17 & Acinetobacter johnsonii DSM 6963(T) & X81663 & 100 \\
\hline & 3 & Acinetobacter guillouiae ATCC 11171(T) & X81659 & 99 \\
\hline & 5 & Acinetobacter junii LMG 998(T) & AM410704 & 100 \\
\hline & 11 & Leclercia adecarboxylata GTC 1267(T) & AB273740 & 100 \\
\hline & 5 & Aeromonas punctata subsp. caviae ATCC $15468(\mathrm{~T})$ & X74674 & 100 \\
\hline & 5 & Aeromonas veronii ATCC 35624(T) & X60414 & 100 \\
\hline & 5 & Enterobacter cancerogenus LMG 2693(T) & Z96078 & 99 \\
\hline & 4 & Pseudomonas balearica $\mathrm{SP} 1402(\mathrm{~T})$ & U26418 & 100 \\
\hline & 1 & Pseudomonas knackmussii $\mathrm{B} 13(\mathrm{~T})$ & AF039489 & 100 \\
\hline & 3 & Psychrobacter pulmonis CECT 5989(T) & AJ437696 & 100 \\
\hline & 4 & Citrobacter murliniae CDC 2970-59(T) & AF025369 & 100 \\
\hline & 2 & Pectobacterium wasabiae ATCC 43316(T) & U80199 & 97 \\
\hline & 1 & Arenimonas composti TR7-09(T) & AM229324 & 97 \\
\hline & 1 & Enhydrobacter aerosaccus LMG 21877(T) & AJ550856 & 99 \\
\hline \multirow[t]{12}{*}{ Alphaproteobacteria } & 18 & & & \\
\hline & 5 & Rhizobium pusense NRCPB10(T) & FJ969841 & 100 \\
\hline & 2 & Brevundimonas vesicularis LMG 2350(T) & AJ227780 & 100 \\
\hline & 2 & Microvirga aerophila $5420 \mathrm{~S}-12(\mathrm{~T})$ & GQ421848 & 95 \\
\hline & 2 & Microvirga subterranea DSM 14364(T) & FR733708 & 97 \\
\hline & 1 & Microvirga flocculans $\mathrm{TFB}(\mathrm{T})$ & AB098515 & 98 \\
\hline & 1 & Altererythrobacter ishigakiensis JPCCMB0017(T) & AB363004 & 97 \\
\hline & 1 & Methylobacterium brachiatum $\mathrm{B} 0021(\mathrm{~T})$ & AB175649 & 100 \\
\hline & 1 & Paracoccus stylophorae KTW-16(T) & GQ281379 & 98 \\
\hline & 1 & Rhodovulum euryhalinum DSM 4868(T) & D16426 & 97 \\
\hline & 1 & Sphingomonas koreensis JSS26(T) & AF131296 & 98 \\
\hline & 1 & Sphingomonas molluscorum KMM 3882(T) & AB248285 & 97 \\
\hline \multirow[t]{6}{*}{ Betaproteobacteria } & 5 & & & \\
\hline & 1 & Bordetella avium $197 \mathrm{~N}$ & AM167904 & 99 \\
\hline & 1 & Comamonas terrigena LMG 1253(T) & AJ430342 & 100 \\
\hline & 1 & Methylophilus flavus Ship(T) & FJ872108 & 100 \\
\hline & 1 & Ramlibacter henchirensis TMB834(T) & AF439400 & 97 \\
\hline & 1 & Variovorax dokdonensis DS-43(T) & DQ178978 & 99 \\
\hline \multirow[t]{13}{*}{ Firmicutes } & 54 & & & \\
\hline & 12 & Planococcus rifietensis $\mathrm{M} 8(\mathrm{~T})$ & AJ493659 & 100 \\
\hline & 2 & Planococcus donghaensis JH 1(T) & EF079063 & 97 \\
\hline & 1 & Planococcus citreus NCIMB 1493(T) & $\mathrm{X} 62172$ & 99 \\
\hline & 1 & Planococcus maritimus $\mathrm{TF}-9(\mathrm{~T})$ & AF500007 & 100 \\
\hline & 13 & Paenisporosarcina macmurdoensis $\mathrm{CMS} 21 \mathrm{w}(\mathrm{T})$ & AJ514408 & 100 \\
\hline & 3 & Planomicrobium koreense JG07(T) & AF144750 & 100 \\
\hline & 2 & Planomicrobium glaciei 423(T) & EU036220 & 100 \\
\hline & 3 & Planomicrobium chinense DX3-12(T) & AJ697862 & 100 \\
\hline & 1 & Planomicrobium okeanokoites IFO 12536(T) & D55729 & 99 \\
\hline & 2 & Anaerotruncus colihominis DSM 17241(T) & ABGD02000032 & 95 \\
\hline & 2 & Bacillus vallismortis DSM 11031(T) & AB021198 & 100 \\
\hline & 2 & Pseudoflavonifractor capillosus ATCC 29799(T) & AAXG02000048 & 98 \\
\hline
\end{tabular}




\begin{tabular}{|c|c|c|c|c|}
\hline Group & Number of clones & The closest match & Accession No. & Sequence similarity $\%$ \\
\hline \multirow{24}{*}{ Actinobacteria } & 2 & Robinsoniella peoriensis $\mathrm{PPC} 31(\mathrm{~T})$ & AF445285 & 96 \\
\hline & 2 & Staphylococcus hominis subsp. hominis DSM 20328(T) & X66101 & 100 \\
\hline & 1 & Alkalibacterium kapii $\mathrm{T} 22-1-2(\mathrm{~T})$ & AB294171 & 98 \\
\hline & 1 & Atopostipes suicloacalis $\mathrm{PPC} 79(\mathrm{~T})$ & AF445248 & 95 \\
\hline & 1 & Finegoldia magna CCUG 17636(T) & AF542227 & 100 \\
\hline & 1 & Paenibacillus agaridevorans DSM 1355(T) & AJ345023 & 98 \\
\hline & 2 & Roseburia intestinalis L1-82(T) & AJ312385 & 95 \\
\hline & 29 & & & \\
\hline & 5 & Arthrobacter sulfonivorans ALL(T) & AF235091 & 99 \\
\hline & 3 & Arthrobacter agilis DSM 20550(T) & X80748 & 100 \\
\hline & 2 & Arthrobacter bergerei CIP 108036(T) & AJ609630 & 100 \\
\hline & 3 & Arthrobacter sulfureus DSM 20167(T) & X83409 & 100 \\
\hline & 3 & Ornithinicoccus hortensis KHI 0125(T) & Y17869 & 98 \\
\hline & 2 & Aeromicrobium erythreum NRRL B-3381(T) & AF005021 & 99 \\
\hline & 2 & Corynebacterium lipophiloflavum DSM 44291(T) & ACHJ01000075 & 100 \\
\hline & 1 & Agrococcus jenensis DSM 9580(T) & X92492 & 100 \\
\hline & 1 & Cellulomonas aerilata $5420 \mathrm{~S}-23(\mathrm{~T})$ & EU560979 & 100 \\
\hline & 1 & Geodermatophilus obscurus DSM 43160(T) & CP001867 & 99 \\
\hline & 1 & Microlunatus panaciterrae Gsoil 954(T) & $\mathrm{AB} 271051$ & 97 \\
\hline & 1 & Nocardioides islandensis MSL 26(T) & EF466123 & 98 \\
\hline & 1 & Sporichthya brevicatena IFO 16195(T) & AB006164 & 95 \\
\hline & 1 & Streptomyces resistomycificus NBRC 12814(T) & AB184166 & 100 \\
\hline & 1 & Tessaracoccus profundi $\mathrm{CB} 31(\mathrm{~T})$ & FJ228690 & 98 \\
\hline & 1 & Yonghaparkia alkaliphila KSL-113(T) & DQ256087 & 100 \\
\hline \multirow{14}{*}{$\begin{array}{l}\text { Cytophaga/ } \\
\text { Flavobacterium/ } \\
\text { Bacteroides }\end{array}$} & 23 & & & \\
\hline & 6 & Segetibacter koreensis Gsoil 664(T) & AB267478 & 98 \\
\hline & 3 & Segetibacter aerophilus 6424S-61(T) & GQ421847 & 97 \\
\hline & 2 & Adhaeribacter terreus DNG6(T) & EU682684 & 99 \\
\hline & 1 & Adhaeribacter aquaticus MBRG1.5(T) & AJ626894 & 97 \\
\hline & 1 & Adhaeribacter terreus DNG6(T) & EU682684 & 95 \\
\hline & 2 & Bacteroides nordii WAL 11050(T) & AY608697 & 95 \\
\hline & 2 & Dysgonomonas mossii DSM 22836(T) & ADLW01000023 & 95 \\
\hline & 1 & Aequorivita sublithincola 9-3(T) & AF170749 & 97 \\
\hline & 1 & Cloacibacterium normanense CCUG 46293(T) & AJ575430 & 99 \\
\hline & 1 & Flavobacterium swingsii WB 2.3-68(T) & AM934651 & 96 \\
\hline & 1 & Ohtaekwangia koreensis 3B-2(T) & GU117702 & 95 \\
\hline & 1 & Parasegetibacter luojiensis RHYL-37(T) & EU877263 & 97 \\
\hline & 1 & Rhodocytophaga aerolata 5416T-29(T) & EU004198 & 98 \\
\hline \multirow[t]{9}{*}{ Uncultured bacteria } & 16 & & & \\
\hline & 3 & Uncultured bacterium & EU289421 & 99 \\
\hline & 2 & Uncultured bacterium & JF429066 & 98 \\
\hline & 2 & Uncultured actinobacterium & EF016801 & 98 \\
\hline & 1 & Uncultured actinobacterium & FJ764201 & 98 \\
\hline & 1 & Uncultured Acidobacteria bacterium & EU979093 & 98 \\
\hline & 1 & Uncultured Acidobacteria bacterium & HQ597451 & 98 \\
\hline & 1 & Uncultured Acidobacteria bacterium & JN038624 & 98 \\
\hline & 1 & Uncultured bacterium & EF445161 & 92 \\
\hline
\end{tabular}




\begin{tabular}{lllll}
\hline Group & Number of clones & The closest match & Accession No. & Sequence similarity\% \\
\hline 1 & Uncultured bacterium & FJ479325 & 99 \\
1 & Uncultured bacterium & FJ534972 & 94 \\
1 & Uncultured bacterium & HQ910257 & 98 \\
1 & Uncultured bacterium & FJ444700 & 99 \\
\hline
\end{tabular}

Aeromonas veronii group revealed by host interaction and DNA sequence data. Plos One 6.

Strobel G, Daisy B, Castillo U, Harper J (2004) Natural products from endophytic microorganisms. J Nat Prod 67:257-268.

Tamura K, Peterson D, Peterson N, Stecher G, Nei M, Kumar S (2011) MEGA5: Molecular evolutionary genetics analysis using maximum likelihood, evolutionary distance, and maximum parsimony methods. Mol Biol Evol 28:2731-2739.

Thompson JD, Higgins DG, Gibson TJ (1994) CLUSTAL W: improving the sensitivity of progressive multiple sequence alignment through sequence weighting, position-specific gap penalties and weight matrix choice. Nucleic Acids Res 22:4673-4680.

Thompson RM, Strong FM (1971) Identification of erythromycin-a in cultures of Streptomyces griseoplanus. Biochem Bioph Res Co 43:213-216.

Velazquez-Becerra C, Iveth Macias-Rodriguez L, Lopez-Bucio J, Altamirano-Hernandez J, Flores-Cortez I, Valencia-Cantero E (2011) A volatile organic compound analysis from Arthrobacter agilis identifies dimethylhexadecylamine, an amino-containing lipid modulating bacterial growth and Medicago sativa morphogenesis in vitro. Plant Soil 339:329-340.
Wang HK, Shao J, Wei YJ, Zhang L, Qi W (2011) A novel low-temperature alkaline lipase from Acinetobacter johnsonii LP28 suitable for detergent formulation. Food Technol Biotech 49:96-102.

Wang ZR, Sheng JP, Tian XL, Wu TT, Liu WZ, Shen L (2011) The in vitro antioxidant properties of Bacillus simplex XJ-25 isolated from sand biological soil crusts. Afr J Microbiol Res 5:4780-4786.

Xie Z, Ge S, Hong D (1999) Preparation of DNA from silica gel dried mini-amount of leaves of Oryza rufipogon for RAPD study and total DNA bank construction. Acta Bot Sin 41:802-807.

Yang X, Chen X, Xu X, Zeng R (2011) Cold-adaptive alkaline protease from the psychrophilic Planomicrobium sp. 547: enzyme characterization and gene cloning. Adv Polar Sci 22:49-54.

Yi YJ, Liu JY (2007) Photochemical analysis of PSII in response to dehydration and

rehydration in moss Grimmia pilifer P. Beauv Acta Ecol Sin 27:5238-5244. (in Chinese)

Yoon JH, Kang SS, Lee KC, Lee ES, Kho YH, Kang KH, Park YH (2001) Planomicrobium koreense gen. nov., sp. nov., a bacterium isolated from the Korean traditional fermented seafood jeotgal, and transfer of Planococcus okeanokoites

Table 2 - The cultivable endophytic bacteria isolated from Grimmia montana.

\begin{tabular}{|c|c|c|c|c|}
\hline Group & No. of isolates & The closest match & Accession No. & Sequence similarity $\%$ \\
\hline \multirow[t]{6}{*}{ Gammaproteobacteria } & 21 & & & \\
\hline & 11 & Pseudomonas azotoformans IAM1603(T) & D84009 & 99.7 \\
\hline & 7 & Pseudomonas libanensis CIP 105460(T) & AF057645 & 99.5 \\
\hline & 1 & Pseudomonas graminis DSM 11363(T) & Y11150 & 99.9 \\
\hline & 1 & Pseudomonas koreensis Ps9-14 (T) & AF468452 & 99.9 \\
\hline & 1 & Yersinia intermedia ATCC 29909(T) & AF366380 & 99.4 \\
\hline \multirow[t]{4}{*}{ Alphaproteobacteria } & 5 & & & \\
\hline & 1 & Sphingomonas aquatilis JSS7(T) & AF131295 & 98.8 \\
\hline & 2 & Sphingomonas azotifigens NBRC 15497(T) & AB217471 & 99.9 \\
\hline & 2 & Sphingomonas melonis DAPP-PG 224(T) & AB055863 & 98.7 \\
\hline \multirow[t]{3}{*}{ Betaproteobacteria } & 12 & & & \\
\hline & 1 & Burkholderia glathei ATCC 29195(T) & Y17052 & 97.1 \\
\hline & 11 & Massilia brevitalea byr23-80(T) & EF546777 & 97.9 \\
\hline \multirow[t]{4}{*}{ Actinobacteria } & 9 & & & \\
\hline & 6 & Curtobacterium flaccumfaciens LMG 3645(T) & AJ312209 & 100 \\
\hline & 2 & Curtobacterium herbarum $\mathrm{P}$ 420/07(T) & AJ310413 & 99.3 \\
\hline & 1 & Streptomyces griseoplanus AS 4.1868(T) & AY999894 & 99.9 \\
\hline \multirow[t]{2}{*}{ Firmicutes } & 2 & & & \\
\hline & 2 & Bacillus simplex NBRC $15720(\mathrm{~T})$ & AB363738 & 99.9 \\
\hline
\end{tabular}


(Nakagawa et al., 1996) and Planococcus mcmeekinii (Junge et al., 1998) to the genus Planomicrobium. Int J Syst Evol Microbiol 51:1511-1520.

Zhang DC, Liu HC, Xin YH, Yu Y, Zhou PJ, Zhou YG (2009) Planomicrobium glaciei sp. nov., a psychrotolerant bacte- rium isolated from a glacier. Int J Syst Evol Microbiol 59:1387-1390.

Zhang JY, Liu XY, Liu SJ (2009) Adhaeribacter terreus sp. nov., isolated from forest soil. Int $\mathrm{J}$ Syst Evol Microbiol 59:1595-1598.

All the content of the journal, except where otherwise noted, is licensed under a Creative Commons License CC BY-NC. 